\title{
Impact of climatic fluctuations on Characeae biomass in a shallow, restored lake in The Netherlands
}

\author{
Winnie J. Rip · Maarten R. L. Ouboter • \\ Hans J. Los
}

(C) Springer Science+Business Media B.V. 2007

\begin{abstract}
External phosphorus load to a wetland with two shallow lakes in the Botshol Nature Reserve, The Netherlands, was reduced, resulting in a rapid reduction of phytoplankton biomass and turbidity, and after 4 years, explosive growth of Characeae. The clear water state was unstable, however, and the ecosystem then alternated between clear, high-vegetation and turbid, lowvegetation states. A model of water quality processes was used in conjunction with a 14-year nutrient budget for Botshol to determine if fluctuations in precipitation and nutrient load caused the ecosystem instability. The results indicate that, during wet winters when groundwater level rose above surface water level, phosphorus from runoff was stored in the lake bottom and banks. Stored phosphorus was released the following spring and summer under anaerobic sediment conditions, resulting in increased phytoplankton density and
\end{abstract}

Guest editors: R. D. Gulati, E. Lammens, N. De Pauw \& E. Van Donk

Shallow lakes in a changing world

W. J. Rip $(\bowtie) \cdot$ M. R. L. Ouboter

Waternet (Water board Amstel Gooi en Vecht),

P.O. Box 94370, 1090 GJ Amsterdam,

The Netherlands

e-mail:winnie.rip@waternet.nl

Hans J. Los

Delft Hydraulics, P.O. Box 177, 2600 MH Delft,

The Netherlands light attenuation in the water column. During years with high net precipitation, flow from land to surface water also transported humic acids, further increasing light attenuation. In years with dry winters, the phosphorus and humic acid loads to surface water were reduced, and growth of submerged macrophytes was enhanced by clear water. Thus, the temporal pattern of precipitation and flow from land to water gave a coherent, quantitative explanation of the observed dynamics in phosphorus, phytoplankton, turbidity, and Characeae. Global warming has caused winters in The Netherlands to become warmer and wetter during the last 50 years, increasing flow from land to water of humic acids and phosphorus and, ultimately, enhancing instability of Characeae populations. In the first half of the 20th century interannual variation in precipitation was not sufficient to cause large changes in internal $\mathrm{P}$ flux in Botshol, and submerged macrophyte populations were stable.

Keywords Chara . Runoff from land to water . Humic acids - Lake $\cdot$ Light attenuation . Nutrient loading · Phosphorus · Phytoplankton · Precipitation - Turbidity - Climate change

\section{Introduction}

The presence of Characeae indicates a healthy aquatic ecosystem. Similar to other aquatic 
macrophytes, Chara and related species support other biological components of the lake ecosystem (Timms \& Moss, 1984; Carpenter \& Lodge, 1986; Noordhuis et al., 2002). Submerged macrophytes also help to maintain high water transparency by a number of mechanisms (Scheffer, 1998). The benthic plants, for example, prevent resuspension of the sediment by wind or fish, compete with phytoplankton for nutrients, and offer refuge to grazing zooplankton (Moss, 1990; Scheffer et al., 1993; Van den Berg et al., 1998; Kufel \& Kufel, 2002). Some species have allelopathic effects on competing epiphytes and phytoplankton (Van Donk \& van de Bund, 2002). Poor light availability, due to shading by phytoplankton and epiphytes, is mostly the primary reason for the disappearance of submerged macrophytes (Philips et al., 1978). Factors other than light, such as grazing (Mitchell \& Perrow, 1998) or phytotoxicity by free sulphide (Lamers et al., 1998), may also be important in determining macrophyte abundance; however, when light is insufficient, macrophytes cannot exist at all.

Shallow lakes can have alternative stable states (Scheffer et al., 1993). Most of these lakes are either rather turbid without submerged macrophytes or clear and vegetated. In some lakes repeated shifts between a clear-vegetated and a turbid state have been observed (Lake Tåkern \& Lake Krankesjön (Blindow et al., 1993), Alderfen broad (Perrow et al., 1994), Tomahawk Lagoon (Mitchell, 1998) and Botshol (Rip et al., 2005). In most lakes the shifts between clear and turbid states occur irregularly in time, suggesting that there is an infrequence external forcing, for instance by water level fluctuations or changes in external phosphorus load. Alternatively, high oxygen consumption by decomposition of macrophyte biomass accumulated during high production years can trigger the anaerobic release of phosphorus, and the resulting phytoplankton blooms limit subsequent macrophyte production (Asaeda et al., 2000). Moss (1990) suggested this intrinsic process for the regular cycles in Alderfen broad. Van Nes et al. (submitted) studied intrinsic processes triggered by submerged macrophytes that according to the "slow-fast theory (Muratori \& Rinaldi, 1991) could cause regular cycles between clear and turbid states in shallow lakes. The present study examined the hypothesis that variation in precipitation and subsequent nutrient loading through runoff account for fluctuations in phosphorus, phytoplankton biomass, light attenuation, and macrophyte abundance.

A previous study (Rip et al., submitted) developed water and nutrient budgets for the entire Botshol ecosystem under the prevailing meteorological conditions. The models provided monthly estimates of nutrient loading during 1989-2002 and, ultimately, insight into the causes of interannual fluctuations in $\mathrm{P}$ loading. The results indicated that, during wet winters when groundwater level rose above the level of surface water in the catchment areas, water flowed from land into surface water, resulting in a rise of the $\mathrm{P}$ load. In dry winters, infiltration through the soil exceeded precipitation, and there was no flow from land to water, so fluctuations in P load were mainly due to the water supply.

The present study extended the nutrient budget to examine fluctuations in phosphorus loading to the two lakes of Botshol as a possible cause of instability in water clarity and abundance of submerged macrophytes. These two studies combined used an ecosystem approach, starting with $P$ loading from catchment areas and transport to surface water, then incorporating biological processes that determine phytoplankton biomass, turbidity, and finally, biomass of Characeae.

\section{Study area and methods}

Hydrology and restoration of Botshol

The hydrology of Botshol, a nature reserve in the center of the Netherlands $\left(52^{\circ} 15^{\prime} \mathrm{N} 4^{\circ} 26^{\prime} \mathrm{E}\right)$ is dominated by infiltration. The area is a hydrologically isolated polder. On average, the water table in Botshol drops $1.75 \mathrm{~mm} \mathrm{day}^{-1}$ by water infiltrating to an adjacent polder, Groot Mijdrecht, which has water levels $4.3 \mathrm{~m}$ below Botshol. There is a strong gradient of infiltration within the nature reserve. Infiltration from the lakes directly bordering Groot Mijdrecht is $2.5 \mathrm{~mm} \mathrm{day}^{-1}$, while infiltration in the northwest part of Botshol is $0.1 \mathrm{~mm} \mathrm{day}^{-1}$. During spring and summer, approximately $10^{6} \mathrm{~m}^{3} \mathrm{P}$ rich water enters Botshol 
to compensate for water lost through evaporation and infiltration. Prior to November 1988 three agricultural areas drained their excess water into Botshol resulting in a high nutrient load.

Up to until 1960, the lakes of the Botshol Nature Reserve were clear and dominated by Characeae. Beginning in the 1960s, water quality deteriorated due to the rise of external phosphorus input, and submerged macrophyte populations declined (Simons et al., 1994). Beginning in 1989, the external nutrient load was reduced by hydrological segregation of Botshol from the agricultural areas and by chemical stripping of $60-80 \%$ of phosphate from the water supply. The goal of restoration was to re-establish the Characeae and other submerged macrophytes. In the first 4 years after the start of phosphorus reduction, decreases were observed in phosphorus and chlorophyll $a$ concentrations. Reduced phytoplankton numbers resulted in crystal clear water and explosive growth of submerged macrophytes (Rip et al., 1992; Simons et al., 1994). The dominant macrophyte species in terms of lake areal cover were Najas marina, Fontinalis antipyretica, Chara connivens, Chara contraria, Chara hispida and Chara globularis. However, this clear water state was unstable. From 1993 onwards, the ecosystem alternated between turbid water with low macrophyte cover (1993-1995, 1999-2003) and clear water with high cover of aquatic plants (1996-1998). Phosphorus concentrations in Botshol showed concomitant fluctuations (Rip et al., 2005). The composition of the fish community was determined in 1989 and 1992. The fish community was not dominated by planktivorous fish or benthivorous fish, such as bream (Abramis brama). Rather, perch, pike, and roach, species typical of clear water lakes with macrophytes, were dominant in Botshol in both surveys (Rip et al., 2005). Total fish biomass decreased over the first 4 years following the reduction of the external P-load.

Physical, chemical and biological parameters

From 1988 through 2003, samples for physical and chemical parameters (temperature, $\mathrm{pH}$, conductivity, Secchi disc depth, attenuation, oxygen, chlorophyll $a$, chloride, total and dissolved $\mathrm{P}$, total and Kjeldahl N, ammonium, nitrate, silicate, and dissolved organic substances [humic acids]) were taken every 2-4 weeks in 5 subareas of Botshol, the main water supply, and Lake Vinkeveen. Phytoplankton and zooplankton densities were determined, simultaneously with the chemical samples at the two lakes (subareas I and II). In the period 1993-1999 no data for attenuation were available. Meteorological data were provided by KNMI (a national meteorological institute). Submerged macrophytes were mapped and quantified each summer 1987-2003. A transect pattern covering most of the open water and pools, watercourses and ditches was followed for each survey. Plant material was observed and collected by dredging and snorkelling from a rowing boat. Characeae species were identified according to Van Raam (2003) . Detailed methods and results of the environmental and biological measurements were presented in Rip et al. (2005).

\section{Model}

The study area of Botshol was divided into five subareas. Subareas III, IV and V were catchment areas for subareas I and II, in which the two lakes were situated. Water and nutrient budgets constructed for each subarea and for the entire study area (Rip et al., submitted) were used as the basis for the ecosystem model developed in the present study.

DELWAQ-BLOOM-SWITCH (DBS), a mathematical model, was used to determine interactions between nutrient loading and transport, and other physical, chemical, and biological processes in the Botshol. The present study used the standard DBS model, which has been successfully applied to similar aquatic ecosystems (Los, 1993; Van der Molen et al., 1994). A general overview of DBS is given below. More detailed information can be found in the technical reference manual for DBS (Los, 1993). A small number of adjustments were made to model the specific situation in Botshol using measurements from 1989-1996. The accuracy of the calibrated model was validated using data from 1997-2002.

DBS modeled the cycling of carbon, oxygen, and nitrogen, phosphorus, and silicon within the 
Botshol ecosystem, adhering to the law of conservation of mass. Nutrients in the water column could be dissolved forms, detritus components and non-detritus organic components. A portion of each nutrient pool was incorporated in the algae. Phosphorus could also be adsorbed to inorganic material (AAP). The module, SWITCH, computed the sediment-water exchange for nutrients by adsorption-desorption (Smits \& Van der Molen, 1993). Nutrients could be recycled an infinite number of times with losses only through transport, chemical adsorption, denitrification, and burial in the sediment. Nutrients could also be transformed through mineralization, sedimentation, resuspension, and nitrification.

Oxygen concentration played an important role in controlling the $\mathrm{P}$ flux from the sediments of Botshol. A large percentage of the $\mathrm{P}$ from runoff was in the particulate state, resulting in $\mathrm{P}$ enrichment of the sediments. Following winters that had high precipitation, anaerobic conditions in the small watercourses in spring/summer resulted in the release of the stored $\mathrm{P}$ from the sediments.

The BLOOM portion of DBS computed phytoplankton production based on competition among algal species (Los \& Brinkman, 1988; Los, 2005). The primary state variables of the BLOOM module were different phytoplankton types. Four taxonomic groups were distinguished: Chlorophyta, Bacillariophyta, Cyanophyta, and Characeae.

BLOOM first selected the factor that was most likely to become limiting, based on environmental conditions: solar radiation, day length, water temperature, depth, background light attenuation, and nutrient concentrations. The model then selected the best-adapted phytoplankton types under those conditions. The biomass of these phytoplankton types were calculated as the net result of production, mortality, and transport during the previous time step using an optimization technique (Linear Programming).

DBS included a module called UITZICHT (Los, 1993; Buiteveld, 1995) that computed light attenuation. Total light attenuation in the water column was the sum of background attenuation and attenuation due to free floating phytoplankton, algal detritus and humic acids.

\section{Results}

Results are shown only for subarea I, but similar agreement between empirical and calculated values was found for the other subareas. Results of chloride calculations showed that the ratios of water supplies and the calculated exchange among subareas used in the water budget were accurate (Fig. 1). The interannual variation of the calculated dynamics of total phosphorus and chlorophyll were similar enough to actual concentrations to show year-to-year differences (Figs. 2, 3): low levels in 1989-1992, high levels in 1993-1995, low levels again in 1996-1998, etc. Both observed and calculated values showed a summer peak each year.

The pattern in 1998 was deviant from other years, probably due to high precipitation in this summer. The calculated values showed a sharp shift to high $\mathrm{P}$ and chlorophyll levels in late summer of that year.

Peaks and low points in chlorophyll $a$ concentration predicted by the model corresponded well with periods of high and low levels measured in the field. In periods with high cover of Characeae, such as the summers of 1991, 1992, and 1998, predicted chlorophyll levels were higher than the observed values. This was probably due to the lack of some feedback processes in DBS. Dense Chara populations during those summers, for example, could have provided shelter for grazing zooplankton or could have influenced phytoplankton by allelopathic effects or increasing the sedimentation rate of phytoplankton. However, biological feedback processes were not completely lacking in the model. Phosphorus

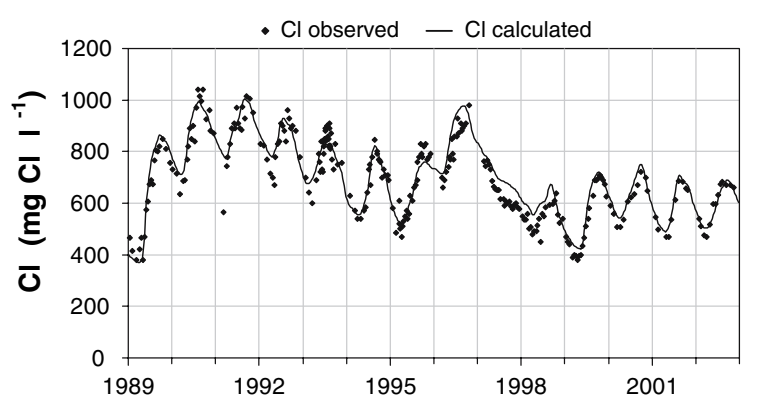

Fig. 1 Observed and calculated chloride levels at location I for 1989-2002 


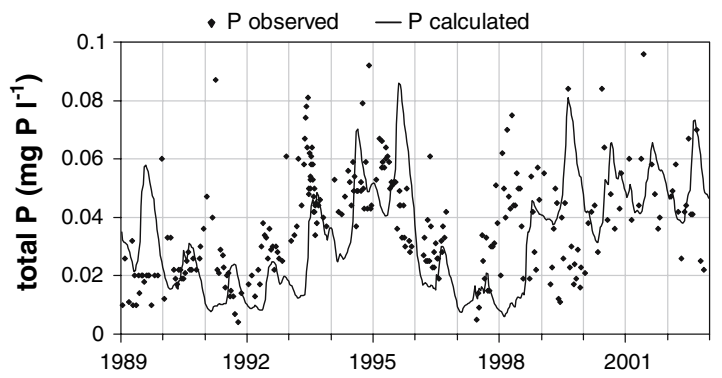

Fig. 2 Observed and calculated total P levels at location I for 1989-2002

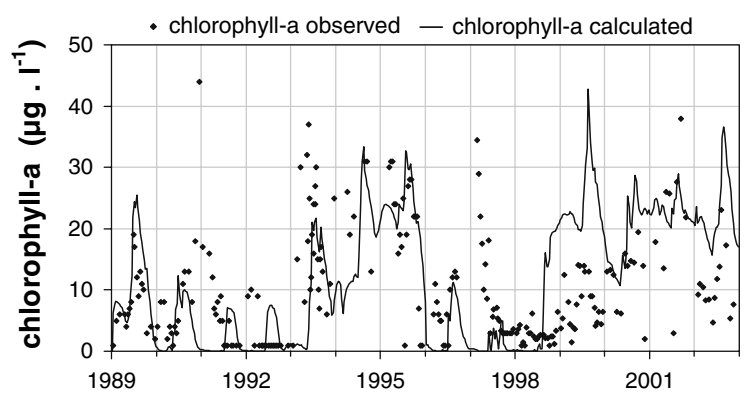

Fig. 3 Observed and calculated chlorophyll levels at location I for 1989-2002

calculated to be stored in Chara, for example, was not available for other algae and predicted light attenuation was affected by free-floating algae, but not by the bottom dwelling Chara. Another example of feedback in the model concerned the relatively slow reaction of particular nutrients stored in the sediment, from decaying algae, to external forcing imposed on the lake system. The result was that the predicted remineralization flux from the sediment in a particular year was clearly affected by the previous years loadings.

Calculated and measured light attenuation were more similar during periods of high and low turbidity. Results of the model, UITZICHT, indicated that temporal variation in light attenuation was determined primarily by variation in amounts of dead (detritus) and living algae (Fig. 5). Humic acids influenced attenuation during years with high precipitation, such as 19931995 and 1999-2002.

The DBS model was not very accurate in calculating Secchi disc depth, although interannual variation in turbidity was successfully predicted (Fig. 4). The generally low algal biomass in

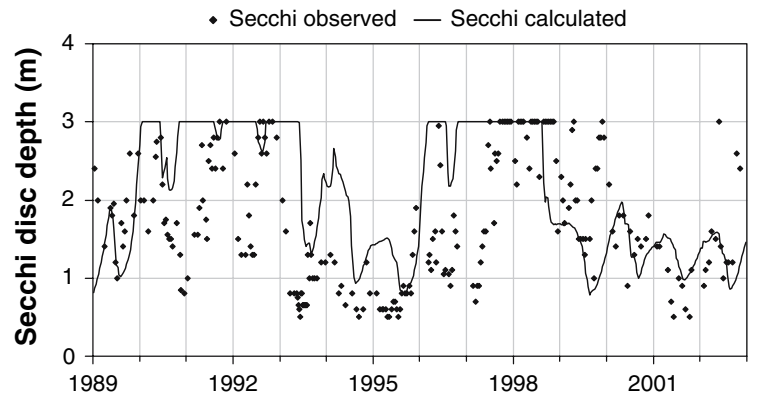

Fig. 4 Observed and calculated Secchi-disc depths at location I for 1989-2002

Botshol, the lack of some feedback processes and the inaccuracy of Secchi disc depth measurements made comparison with simulations difficult. Secchi disc depths calculated for the entire years of 1991 and 1992 were at bottom depth, for example, while actual values varied.

The model's predictions of fluctuations in Chara biomass agreed with fluctuations in percent cover of Chara determined in the field (Fig. 6). Both calculated and observed levels were high, for example, in 1991, 1992, 1997, and 1998, and low in 1994, 1995, and 1999-2002. The model overestimated the biomass of Chara during 1993 and 1996, corresponding to overestimates of Secchi disc depth.

The runoff in dry years was about $90 \%$ reduced in comparison to wet years (Rip et al., submitted). To test the hypothesis that $\mathrm{P}$ loading to surface water through flow from land to water, especially after winters with high precipitation, was a major factor causing reduced cover of Chara in the lakes of Botshol, the model was run under the condition that the $\mathrm{P}$ concentration in water flow from land to surface water was reduced $90 \%$. The $\mathrm{P}$ load from water inflow to maintain water level in summer remained the same. During wet years, phosphorus and chlorophyll a levels calculated under this condition were substantially lower than levels calculated under the standard conditions. DBS calculated a stable Chara population each summer.

Overall, the DBS model provided sufficient consistency between computed and measured parameters of the Botshol ecosystem to explain the dynamics of nutrient loading, phytoplankton density, light attenuation, and Chara populations. 
Fig. 5 Observed attenuation and calculated composition of light attenuation at location II for 1989-2002

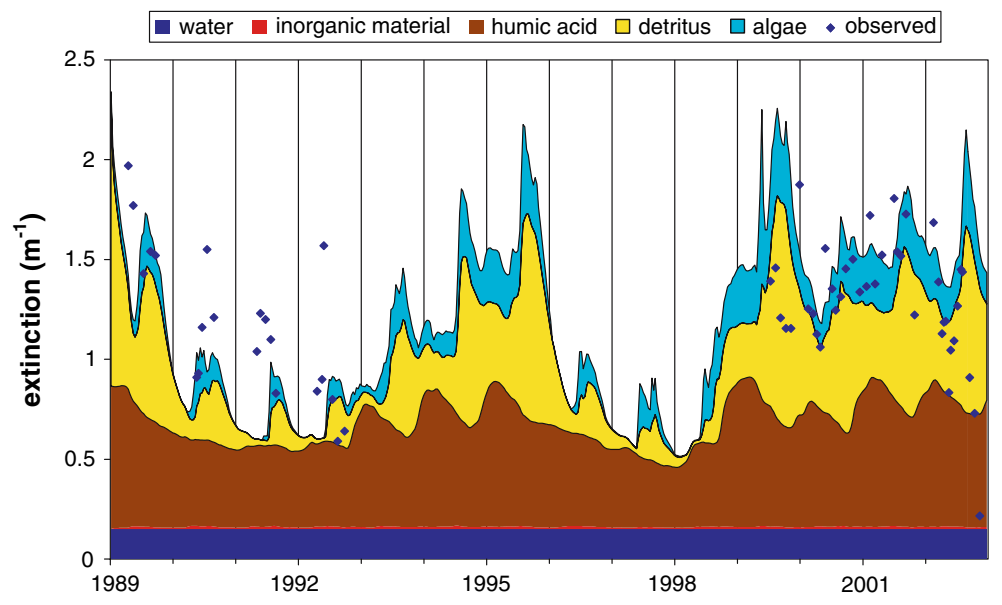

The flow of water which is rich in phosphorus and humic acids from land to water, particularly following periods of high precipitation, is a likely explanation for the instability of the aquatic ecosystem in Botshol after the reduction of the external nutrient load.

\section{Discussion}

The main conclusion from the nutrient budget developed for Botshol was that, following nutrient reduction, $\mathrm{P}$ from flow from land to water acted as the primary internal nutrient source during periods when precipitation exceeded the water loss by infiltration and evaporation (Rip et al., submitted). Although similarity between calculated values and empirical measurements varied somewhat among the parameters (Figs. 1$6)$, results of the calibrated DBS model repro- duced the dynamics of the Botshol ecosystem during 1989-2002 closely enough to provide a useful tool in determining causes of interannual variation.

Results of the present study showed that, during wet years, the P-rich, flow from land to water resulted in increased phosphorus levels and phytoplankton biomass in surface water of Botshol (Figs. 2, 3). In addition to high $\mathrm{P}$ levels, the flow from land to water contained large amounts of dissolved organic substances (humic acids) that colored the water dark brown and further reduced light penetration (Fig. 5). Consequently, light attenuation was so high during periods of high precipitation that Chara populations declined (Fig. 6). After dry winters, the groundwater level in terrestrial peat was below the surface water level, and the internal $\mathrm{P}$ source was eliminated. During the next growing season, water transparency was high, and Chara
Fig. 6 Calculated biomass of Chara $(\mathrm{kg} \mathrm{C})$ as model results and field surveys (\% cover) at subarea I for 1989-2002

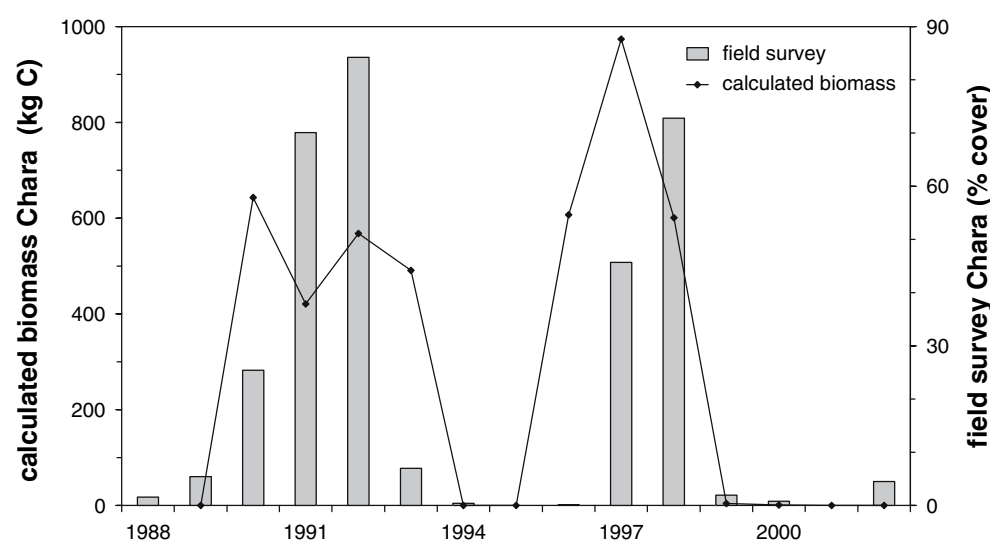


populations increased. This trend was confirmed by the significant negative correlation between Chara cover and net precipitation during the previous 2 years $(r=-0.771, P<0.01)$. In a simulated situation with low precipitation, calculated Chara populations showed an annual cycle that was stable from year to year. Thus, variation in winter precipitation probably caused interannual changes in $\mathrm{P}$ flux and humic acids from terrestrial peat, which explained fluctuations in $\mathrm{P}$ concentration, phytoplankton biomass, and water transparency in Botshol. Hough et al. (1991) have shown similar effects of variation in precipitation on cover of submerged macrophytes.

In principle any lake with a large enough catchment area will have variation in $\mathrm{P}$ load from runoff that is related to variation in precipitation. However, the fluctuation in P load will not always result in a related pattern of high and low cover of submerged macrophytes. In shallow lakes with alternative states there is a range of nutrients in which either a turbid, vegetation poor or a clear, vegetation rich states can exist (Scheffer et al., 1993), sometimes called the "catastrophe fold". Although other factors, like removal of fish, can alter the ecological balance within this range, fluctuations in precipitation and runoff will only cause a switch between clear, vegetated and turbid, unvegetated states if the $\mathrm{P}$ content falls above or below this nutrient range. Thus, the influence of fluctuations in runoff on the cover of Characeae depends on the size of the runoff area, the P load from other sources, and the P load range where both alternative states can exist. This critical range is determined by size, depth, fetch, and sediment type of the lake (Janse, 2005). For example, the critical $\mathrm{P}$ load causing a switch in stable state was markedly lower in deeper lakes than in shallow lakes and the range is smaller. Botshol is relatively deep for lakes in the Netherlands, so the range of critical $\mathrm{P}$ load (0.8$1.3 \mathrm{mg} \mathrm{P} \mathrm{m}^{-2}$ year $^{-1}$, Rip et al., submitted) is relatively low and small and easily exceeded by small changes in P load.

Landscape and physicochemical conditions in the aquatic ecosystem of Botshol account for the large temporal variation and time lags in $\mathrm{P}$ flux. Subsurface flow of P-rich water was most important in subareas IV and V, which had high land/ water ratios and low infiltration rates. Although the catchment areas were not fertilized or used for agricultural purposes, phosphorus concentrations in the peat soil water were high due to mineralization and high chloride and sulfide levels (Beltman et al., 2005; Lamers et al., 1998). The mineralization of the terrestrial peat is not a 'natural' process. Botshol is below sea level and humans stabilized the landscape by influencing the water table. The water table in Botshol was maintained at a constant level by the inflow of water during the summer and outflow of water in winter. The inflowing water had high levels of P, S, and Cl. Starting in 1989, $60-80 \%$ of $\mathrm{P}$ was stripped from the inflowing water. The untreated sulphur and chloride levels remained high, however, and increased the internal availability of $\mathrm{P}$ in Botshol (Lamers et al., 1998; Beltman et al., 2005). As was found in other freshwater systems (Meyer et al., 1981), a high percentage $(-85 \%)$ of $\mathrm{P}$ in runoff was probably particulate material. The particulate $\mathrm{P}$ was stored in the water bottoms and banks of the small watercourses in subarea IV and V, explaining why only a small increase in $\mathrm{P}$ concentration was seen in surface water during wet winters (Fig. 2). When water temperature rose in spring, the stored $\mathrm{P}$ was partly released from bottom sediments. In summer, however, there was an explosive $\mathrm{P}$ flux from the sediments due to low yearly oxygen levels. The small watercourses in subareas IV and $\mathrm{V}$ of Botshol became anaerobic during summer, when mineralization of organic matter in the sediment created a high oxygen demand. When P-rich water from subareas IV and V was subsequently transported to subareas I and II to make up for summer evaporation and infiltration, large amounts of $\mathrm{P}$ were carried into surface waters of the lakes.

Results of the present study provide a likely explanation for the decline in Chara populations during 1993-1995 and 1999-2002. An important condition for the growth of Characeae is light reaching the lake bottom after germination, which occurs around May. This condition was met in Botshol when $\mathrm{P}$ was below $0.018 \mathrm{mg} \mathrm{l}^{-1}$ (Rip et al., 2005) corresponding to periods of high macrophyte cover. When total $\mathrm{P}$ was between 0.018 and $0.043 \mathrm{mg} \mathrm{l}^{-1}$, there were periods of both 
low and high cover of submerged macrophytes (Rip et al., submitted), supporting the hypothesis that either state can exist at intermediate nutrient levels (Scheffer, 1993). After a wet winter, however, $\mathrm{P}$ levels enhanced by subsurface run-off exceeded this range and stimulated growth of phytoplankton, which in turn decreased light penetration and limited growth of Chara.

In addition to light, other factors may influence submerged macrophyte populations, including chloride concentrations (Jeppesen et al., 1994), sediment toxicity due to sulfide (Lamers et al., 1998), grazing by herbivorous birds (Moss, 1990; Mitchell \& Perrow, 1998), and accumulation of organic material of decaying submerged plants (Carpenter \& Lodge, 1986; Perrow et al., 1994; Asaeda et al., 2000). The possible involvement of these factors in the observed interannual fluctuations of Chara in Botshol is examined in other studies (Beltman et al., 2005; Van Nes et al., submitted; Rip et al., unpublished).

The approach taken by the present study considered the ecosystem as a whole, starting with actual meteorological conditions, incorporating transport from land to surface water, as well as changes in phytoplankton and light attenuation, and finally examining effects on submerged macrophytes. In contrast, most previous studies of aquatic systems modeled either nutrient loading (Meyer et al., 1981; Mander et al., 1998) or biological processes (Janse et al., 1997; Best et al., 2001). A few previous studies modeled both, but only for average years and did not examine interannual variation (Asaeda et al., 2000; Portielje \& Rijsdijk, 2003). The present study, therefore, was uniquely able to explain the role of interannual variation in precipitation as a cause of instability in an aquatic ecosystem.

Precipitation became a major factor influencing submerged macrophyte populations only after restoration efforts in Botshol were initiated. Following the reduction in external $\mathrm{P}$ load to very low levels, the internal $\mathrm{P}$ load from subsurface run-off increased in importance as a nutrient source for phytoplankton. As a high percentage of the area of Botshol is terrestrial peat, interannual variation in precipitation caused large changes in the internal $\mathrm{P}$ load to surface water. The high infiltration rate and large ditch distance in much of the terrestrial peat resulted in low runoff and land-to-water $\mathrm{P}$ flow during dry winters (Ouboter \& Rip, submitted). A side effect of the hydrological isolation of Botshol, furthermore, was an increase in chloride from 500 to $1000 \mathrm{mg} \mathrm{l}^{-1}$, which enhanced the availability of phosphorus in peat (Beltman et al., 2005). Finally, the relatively large depths of the lakes in Botshol made submerged macrophyte populations vulnerable to even small increases in light attenuation.

External P loading to Botshol was low, and Characeae populations in Botshol did not exhibit large interannual fluctuations prior to 1960 (Simons et al., 1994). Analysis of the weather in the Netherlands during the 20th century indicated that both temperature and annual precipitation have risen since 1901, related to global changes causing a warmer and wetter climate throughout western Europe (IPCC, 2001; KNMI, 2001). Thus, all winters in which more than $500 \mathrm{~mm}$ of precipitation were recorded in De Bilt, a site in the Netherlands close to Botshol, came after 1960. Before that time, interannual variation in precipitation was not sufficient to cause large changes in internal $\mathrm{P}$ flux in Botshol, and submerged macrophyte populations were stable (Simons et al., 1994).

The first 4 years of the Botshol restoration project (1988-1992) coincided with four dry winters, so the initial change to the clear water state and increased Chara populations were due to the combination of reduced external $\mathrm{P}$ load and low precipitation. The pre-restoration $\mathrm{P}$ load to the lakes was high and reduction of external $\mathrm{P}$ load was necessary to allow growth of submerged macrophytes. Now that the external P load is not a limiting factor, additional measures are needed to decrease internal $\mathrm{P}$ flux in Botshol during wet winters to sustain stable populations of submerged macrophytes. In wet years, internal $\mathrm{P}$ flux could be reduced by allowing the water level to fluctuate more naturally. Desiccation of peat during dry periods, for example, would reduce $\mathrm{P}$ in runoff, due to immobilization of $\mathrm{P}$ by oxidation of Fe (Lucassen et al., 2005). Another approach would be to reverse terrestrialization by removing large areas of terrestrial peat $1 \mathrm{~m}$ below water level. This would reduce the surface area where 
nutrient-rich groundwater can flow into surface water. Finally, the creation of larger areas of surface water in the subareas with the highest runoff would raise oxygen levels, decrease reduction of sulphate to sulphide, and reduce $\mathrm{P}$ release from sediment. Results of the present study demonstrated that the future stability of macrophyte populations in Botshol will depend on improved management of internal $\mathrm{P}$ flux.

Acknowledgements The authors thank the Society for the Preservation of Nature in the Netherlands for permission to perform the research in the Botshol nature reserve, and Jos van Gils, Arjen Markus and Paul Grashoff for discussions and assistance during the development of the models of Botshol. We are grateful to Boudewijn Beltman and Val Gerard for improving the manuscript.

\section{References}

Asaeda, T., V. K. Trung \& J. Manatunge, 2000. Modeling the effects of macrophyte growth and decomposition on the nutrient budget in Shallow Lakes. Aquatic Botany 68: 217-237.

Beltman, B., W. J. Rip \& A. Bak, 2005. Nutrient release after water quality restoration measures. A phytometer assessment in the Botshol wetlands, The Netherlands. Wetlands Ecology and Management 13: $577-$ 585 .

Best, E. P. H., C. P. Buzzelli, S. M. Bartell, R. L. Wetzel, W. A. Boyd, R. D. Doyle \& K. R. Campbell, 2001. Modeling submersed macrophyte growth in relation to underwater light climate: modeling approaches and application potential. Hydrobiologia 444: 43-70.

Blindow, I., G. Andersson, A. Hargeby \& S. Johansson, 1993. Long-term pattern of alternative stable states in two shallow eutrophic lakes. Freshwater Biology 30: 243-252.

Buiteveld, H., 1995. A model for calculation of diffuse light attenuation (PAR) and Sechi depth. Netherlands Journal of Aquatic Ecology 29: 55-65.

Carpenter, S. R. \& D. M. Lodge, 1986. Effects of submersed macrophytes on ecosystem processes. Aquatic Botany 26: 341-370.

Hough, R. A., T. E. Allenson \& D. D. Dion, 1991. The response of macrophyte communities to droughtinduced reduction of nutrient loading in a chain of lakes. Aquatic Botany 41: 299-308.

IPCC, 2001. Climate Change 2001: The Scientific Basis. Cambridge University Press, 892 pp.

Janse, J. H., E. van Donk \& T. Aldenberg, 1997. A model study on the stability of the macrophyte-dominated clear water state as affected by biological factors. Water Research 32: 2696-2706.

Janse, J. H., 2005. Model studies on the eutrophication of shallow lakes and ditches. University of Wageningen. Thesis, 376 pp.
Jeppesen, E., M. Sondergaard, E. Kanstrup \& B. Petersen, 1994. Does the impact of nutrients on the biological structure and function of brackish and freshwater differ? Hydrobiologia 276: 15-30.

KNMI, 2001. De toestand van het klimaat in Nederland 2000 (in Dutch).

Kufel, L. \& I. Kufel, 2002. Chara beds acting as nutrient sinks in shallow lakes-A review. Aquatic Botany 72: 249-260.

Lamers, L. P. M., H. B. M. Tomassen \& J. G. M. Roelofs, 1998. Sulphate-induced eutrophication and phytotoxicity in freshwater wetlands. Environmental Science and Technology 32: 199-205.

Los, F. J. \& J. J. Brinkman, 1988. Phytoplankton modelling by means of optimization: a 10-year experience with Bloom II. Verhandlungen Internationale Verein. Limnologie 23: 790-795.

Los F. J., 1993. DBS. Tech. Rep. T542, Delft Hydraulics, The Netherlands (in Dutch).

Los, F. J., 2005. An algal biomass prediction model. In Daniel, P. Loucks \& Eelco van Beek (eds), Water Resources Systems Planning and Management - an introduction to methods, models and applications. UNESCO, 2005.

Lucassen, C. H. E. T., A. J. P. Smolders \& J. G. M. Roelofs, 2005. Effects of temporary desiccation on the mobility of phosphorus and metals in sulphur-rich fens: differential responses of sediments and consequences for water table management. Wetlands Ecology and Management 13: 135-148.

Mander, Ü., A. Kull, V. Tamm, V. Kusemets \& R. Karjus, 1998. Impact of climatic fluctuations and land use change on runoff and nutrient losses in rural landscapes. Landscape and Urban Planning 41: 229-238.

Meyer, J. L., G. E. Likens \& J. Sloane, 1981. Phosphorus, nitrogen and organic carbon flux in a headwater stream. Archiv für Hydrobiologie 91: 28-44.

Mitchell, S. F. \& M. R. Perrow, 1998. Interactions Between Grazing Birds and Macrophytes. In Jeppesen, E., Ma. Sondergaard, Mo. Sondergaard \& K. Christoffersen (eds), The structuring Role of Submerged Macrophytes in Lakes. Springer Verlag, New York, 175-195.

Moss, B., 1990. Engineering and biological approaches to the restoration from eutrophication in which aquatic plant communities are important components. Hydrobiologia 275(276): 367-377.

Mutatori, S. \& S. Rinaldi, 1991. A separation condition for existence of limit cycles in slow-fast systems. Applied Mathematical Modelling 15: 312-318.

Noordhuis, R., D. T. Van der Molen \& M. S. Van den Berg, 2002. Response of herbivorous water-birds to the return of Chara in Lake Veluwemeer, The Netherlands. Aquatic Botany 72: 349-367.

Perrow, M. R., B. Moss \& J. Stansfield, 1994. Trophic interactions in a shallow lake following a reduction in nutrient loading: A long term study. Hydrobiologia 275: 43-52.

Philips, G. L., D. Eminson \& B. Moss, 1978. A mechanism to account for macrophyte decline in progressively eutrophicated freshwaters. Aquatic Botany 4: 103-126. 
Portielje, R. \& R. E. Rijsdijk, 2003. Stochastic modeling of nutrient loading and lake ecosystem response in relation to submerged macrophytes and benthivorous fish. Freshwater Biology 48: 741-755.

Rip, W. J., K. Everards \& A. Houwers, 1992. Restoration of Botshol (The Netherlands) by reduction of external nutrients load: The effects on physico-chemical conditions, plankton and sessile diatoms. Hydrobiological Bulletin 25: 275-286.

Rip, W. J., M. Ouboter, E. H. van Nes \& B. Beltman, 2005. Oscillation of a shallow lakes ecosystem upon reduction in external phosphorus load. Archiv für Hydrobiologie 164: 387-409.

Scheffer, M., 1998. Ecology of shallow lakes. Population and Community Biology series, Kluwer Academic Publishers, 357 pp.

Scheffer, M., S. H. Hosper, M. L. Meijer, B. Moss \& E. Jeppesen, 1993. Alternative equilibria in shallow lakes. Trends in Ecology and Evolution 8: 275-279.

Simons, J., M. Ohm, R. Daalder, P. Boers \& W. J. Rip, 1994. Restoration of Botshol (The Netherlands) by reduction of external nutrient load: recovery of a characean community, dominated by Chara connivens. Hydrobiologia 275/276: 243-253.

Smits, J. G. C. \& D. T. van der Molen, 1993. Application of SWITCH, a model for sediment-water exchange of nutrients, to Lake Veluwe in the Netherlands. Hydrobiologia 253: 281-300.

Timms, R. M. \& B. Moss, 1984. Prevention of growth of potentially dense phytoplankton populations by zooplankton grazing in the presence of zooplanktivorous fish in a shallow wetland ecosystem. Limnology and Oceanography 29: 472-486.

Van den Berg, M. S., H. Coops, M.-L. Meijer, M. Scheffer \& J. Simons, 1998. Clear water associated with a dense Chara vegetation in the shallow and turbid Lake Veluwemeer, The Netherlands. In Jeppesen, E., Ma. Sondergaard, Mo. Sondergaard \& K. Christoffersen (eds), The Structuring Role of Submerged Macrophytes in Lakes. Ecological Studies. Springer Verlag 131: 339-352.

Van der Molen, D. T., F. J. Los, L. van Ballegooijen \& M. P. van der Vat, 1994. Mathematical modelling as a tool for management in eutrophication control of shallow lakes. Hydrobiologia 275/276: 479-492.

Van Donk, E. \& W. J. van de Bund, 2002. Impact of submersed macrophytes including charophytes on phyto- and zooplankton communities: allelopathy versus other mechanisms. Aquatic Botany 72: 261274.

Van Raam J. C., 2003. Handboek Kranswieren. Chara boek, Hilversum (in Dutch). 